\title{
Prognostic Modeling for Electrical Treeing in Solid Insulation using Pulse Sequence Analysis
}

DOI:

10.1109/CEIDP.2014.6995906

Link to publication record in Manchester Research Explorer

\section{Citation for published version (APA):}

Aziz, N. H., Catterson, V. M., Judd, M. D., Rowland, S. M., Bahadoorsingh, S., \& Analysis, P. M. F. E. T. I. S. I. U. P. S. (2014). Prognostic Modeling for Electrical Treeing in Solid Insulation using Pulse Sequence Analysis. In host publication IEEE. https://doi.org/10.1109/CEIDP.2014.6995906

\section{Published in:}

host publication

\section{Citing this paper}

Please note that where the full-text provided on Manchester Research Explorer is the Author Accepted Manuscript or Proof version this may differ from the final Published version. If citing, it is advised that you check and use the publisher's definitive version.

\section{General rights}

Copyright and moral rights for the publications made accessible in the Research Explorer are retained by the authors and/or other copyright owners and it is a condition of accessing publications that users recognise and abide by the legal requirements associated with these rights.

\section{Takedown policy}

If you believe that this document breaches copyright please refer to the University of Manchester's Takedown Procedures [http://man.ac.uk/04Y6Bo] or contact uml.scholarlycommunications@manchester.ac.uk providing relevant details, so we can investigate your claim.

\section{OPEN ACCESS}


This is the accepted manuscript, which has been accepted by IEEE for publication (C) 2014 IEEE. Personal use of this material is permitted. Permission from IEEE must be obtained for all other uses, in any current or future media, including reprinting/republishing this material for advertising or promotional purposes, creating new collective works, for resale or redistribution to servers or lists, or reuse of any copyrighted component of this work in other works. The full reference is:

'Prognostic Modeling for Electrical Treeing in Solid Insulation using Pulse Sequence Analysis'

N.H. Aziz, V.M. Catterson, M.D. Judd, S. M. Rowland and S. Bahadoorsingh IEEE Conference on Electrical Insulation and Dielectric Phenomena, Des Moines, pp. 373-376 (2014)

DOI: 10.1109/CEIDP.2014.6995906 


\title{
Prognostic Modeling for Electrical Treeing in Solid Insulation using Pulse Sequence Analysis
}

\author{
N.H. Aziz ${ }^{1}$, V.M. Catterson ${ }^{1}$, M.D. Judd ${ }^{1}$, S. M. Rowland ${ }^{2}$ and S. Bahadoorsingh ${ }^{3}$ \\ ${ }^{1}$ Institute for Energy and Environment, University of Strathclyde, Glasgow G1 1XW, United Kingdom \\ ${ }^{2}$ School of Electronic and Electrical Engineering, The University of Manchester, Manchester M13 9PL, United Kingdom \\ ${ }^{3}$ Department of Electrical and Computer Engineering, The University of the West Indies, St Augustine, Trinidad and Tobago
}

\begin{abstract}
This paper presents a prognostic framework for estimating the time-to-failure (TTF) of insulation samples under electrical treeing stress. The degradation data is taken from electrical treeing experiments on 25 epoxy resin samples. Breakdown occurs in all tests within 2.5 hours. Partial discharge (PD) data from 18 samples are used as training data for prognostic modeling and 7 for model validation. The degradation parameter used in this model is the voltage difference between consecutive PD pulses, which decreases prior to breakdown. Every training sample shows a decreasing exponential trend when plotting the root mean squared (RMS) of the voltage difference for 5 minute batches of data. An average model from the training data is developed to determine the RMS voltage difference during breakdown. This breakdown indicator is verified over three time horizons of 25,50 and 75 minutes. Results show the best estimation of TTF for 50 minutes of data, with error within quantified bounds. This suggests the framework is a promising approach to estimating insulation TTF.
\end{abstract}

\section{INTRODUCTION}

The insulation systems of power system equipment are subject to different kinds of stresses during their service life and thus suffer degradation and deterioration. These can lead to a reduction in life, which in turn can lower the reliability of electrical power systems. Therefore, a lot of research effort, activities and publications are directed towards a better understanding of degradation phenomena [1][2], the creation of tools for insulation diagnosis [3][4] and the establishment of remaining life estimation techniques [5][6].

Electrical treeing is one of the main reasons for long term degradation of polymeric materials used in high voltage AC applications. Research has shown that there is a significant relationship between partial discharge (PD) phenomena and the morphology of an electrical tree [2][3]. This study aims to predict the lifetime of solid insulation by experimentally inducing electrical treeing in samples of epoxy resin. Indicators of ageing are features of the PD plot that correspond to electrical tree growth, and can therefore be used to identify the stage of growth and predict remaining life.

In this paper, the pulse sequence analysis (PSA) technique has been applied and shows distinctive features which change with the tree evolution. The basis of pulse sequence analysis is that strong correlations exist between consecutive discharge pulses due to the influence of local space charge on the ignition of the following discharge pulse [3]. Thus, the governing parameters for the discharges are the local electric fields and their changes, which are reflected in the change in voltage due to the excitation waveform. As a result, this paper will focus on changes to external voltage between pulses.

\section{EXPERIMENTAL METHODOLOGY}

In this study, the same electrical treeing samples were used as in [7]. Detailed descriptions of the experimental plan and sample preparation have been outlined in [7] and [8] respectively. Seven different harmonic-influenced test waveforms including the fundamental were utilized, with six point-plane epoxy resin samples exposed to each waveform, giving a total of 42 sets of tree data. The properties of the waveforms are indicated by total harmonic distortion (THD) and waveshape factor $\left(K_{s}\right)$, as described in Table 1 . The phase difference between the harmonic frequencies and the fundamental is zero for all test waveforms.

During the experiment, a branch-type tree was initiated with an $18.0 \mathrm{kV}$ peak, $50 \mathrm{~Hz}$ waveform until the tree reached about $10 \mu \mathrm{m}$ in length. At this stage, the composite waveform was maintained at $14.4 \mathrm{kV}$ peak for a maximum of 2.5 hours, while PD data consisting of phase and discharge magnitude was recorded continuously in 5 minute batches. Out of the 42, only 31 samples reached breakdown within 2.5 hours [7]. Of these, 25 samples were used in this study, due to insufficient PD data from the remaining six. 18 tree samples were utilized for model training, with the remaining seven used for model validation as shown in Table 1.

TABLE I

Properties of SeVen Test Waveforms

\begin{tabular}{|c|c|c|c|c|c|c|}
\hline \multirow[t]{2}{*}{ Wave } & \multicolumn{2}{|c|}{ Composition $+50 \mathrm{~Hz}$} & \multirow[b]{2}{*}{$K_{s}$} & \multirow[b]{2}{*}{$\begin{array}{c}\text { THD } \\
\%\end{array}$} & \multirow[b]{2}{*}{$\begin{array}{c}\text { Training } \\
\text { Data }\end{array}$} & \multirow[b]{2}{*}{$\begin{array}{c}\text { Testing } \\
\text { Data }\end{array}$} \\
\hline & $\begin{array}{l}\text { Harmonic } \\
\text { Order }\end{array}$ & $\begin{array}{c}\text { \% of } \\
\text { Each } \\
\text { Harmonic }\end{array}$ & & & & \\
\hline 1 & 3 & 40.0 & 1.56 & 40.00 & 2 & 1 \\
\hline 7 & 1 & 100.0 & 1.00 & 0.00 & 2 & 1 \\
\hline 8 & 5 & 5.0 & 1.03 & 5.00 & 1 & 1 \\
\hline 9 & 7 & 5.0 & 1.06 & 5.00 & 3 & 1 \\
\hline 11 & 7 & 17.8 & 1.60 & 17.8 & 4 & 1 \\
\hline 12 & $5,7,11,13,23,25$ & 3.2 & 1.60 & 7.85 & 2 & 1 \\
\hline 13 & $5,7,11,13,23,25$ & 2.0 & 1.27 & 5.00 & 4 & 1 \\
\hline
\end{tabular}




\section{Pulse Sequence AnAlysis (PSA)}

In pulse sequence analysis (PSA), the change of external voltage, $\Delta U$, between consecutive PD pulses is considered a key parameter, since it relates to the increase in local electric field that triggers the next partial discharge [3]. In order to determine $\Delta U$, first the instantaneous voltage, $u(t)$, of every PD pulse is calculated using phase position, $\theta$, and one of equations (1) to (7) for test waveforms 1, 7, 8, 9, 11, 12 and 13 in Table 1 as appropriate. $\Delta U$ is then determined using (8).

$$
\begin{aligned}
& u_{1}(t)= 10.25 \sqrt{2}(\sin \theta+0.4 \sin 3 \theta) \\
& u_{7}(t)= 10.18 \sqrt{2}(\sin \theta) \\
& u_{8}(t)= 9.7 \sqrt{2}(\sin \theta+0.05 \sin 5 \theta) \\
& u_{9}(t)= 10.4 \sqrt{2}(\sin \theta+0.05 \sin 7 \theta) \\
& u_{11}(t)= 9.35 \sqrt{2}(\sin \theta+0.178 \sin 7 \theta) \\
& u_{12}(t)= 10.15 \sqrt{2}(\sin \theta+0.032(\sin 5 \theta+ \\
&\sin 11 \theta+\sin 13 \theta+\sin 23 \theta+\sin 25 \theta)) \\
& u_{13}(t)= 10.18 \sqrt{2}(\sin \theta+0.02(\sin 5 \theta+\sin 11 \theta \\
&+\sin 13 \theta+\sin 23 \theta+\sin 25 \theta)) \\
& \Delta U_{i}=u\left(t_{i}\right)-u\left(t_{i-1}\right)
\end{aligned}
$$

The changing pattern of $\Delta U$ can be seen clearly from the $u(t)$ plots in Fig. 1 showing three voltage cycles of test waveform 7 . As the tree approaches breakdown, the number of PD pulses per cycle increases, thus yielding a decreasing value for $\Delta U$. Throughout the treeing process, the range of phase positions where PD occurs increases, and pulses form two dominant clusters in the plots, labeled A and B. Cluster A expands from $1^{\text {st }}$ quadrant only in Fig. 1a to $1^{\text {st }}$ quadrant and half of the $4^{\text {th }}$ quadrant in Fig. 1b. As for Cluster B, the pulses expand from the $3^{\text {rd }}$ quadrant only to half of the $2^{\text {nd }}$ quadrant.

Interestingly, PD stops occurring after reaching the peak voltage, where $\Delta U$ changes from positive to negative or vice versa. Other test waveforms also show the decreasing pattern of $\Delta U$ as the tree grows, but with slightly different behavior because the excitation waveform is non-sinusoidal. Referring to Fig. 2, it can be seen that the polarity change in $\Delta U$ occurs more frequently for a sample tested with waveform 1 (which is non-sinusoidal), giving more points of non-activity in the plot (six points compared to two for waveform 7). However, the general trend of $\Delta U$ decreasing towards breakdown remains.

\section{AgEING INDICATOR}

As mentioned in Section II, the PD data is recorded in 5 minute batches. In order to represent the voltage change during a 5 minute batch, the root mean square (RMS) of the voltage change, $\Delta U_{R M S}$, is calculated using (9). Fig. 3 shows an example of the $\Delta U_{R M S}$ variation during the tree growth.

$$
\Delta U_{r m s}=\sqrt{\frac{1}{n} \sum_{i=1}^{n} \Delta U_{i}^{2}}
$$

Despite the generally decreasing exponential pattern of $\Delta U_{R M S}$, the tree growth can be divided into three stages based on the changing pattern of the plot. Stage 1 in Fig. 3 shows a steep change in $\Delta U_{R M S}$ values until $\Delta U_{R M S}$ equals $1 \mathrm{kV}$. Next, Stage 2 shows a very slight change of $\Delta U_{R M S}$ where the tree branches have touched the ground plate but the sample has not yet reached breakdown. Finally, Stage 3 shows a fluctuation in $\Delta U_{R M S}$ right before the breakdown. For this study, the exponential fit is applied to the whole $\Delta U_{R M S}$ plot.

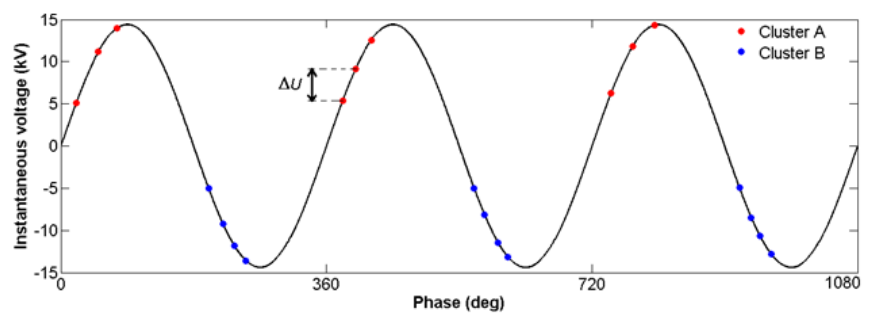

(a)

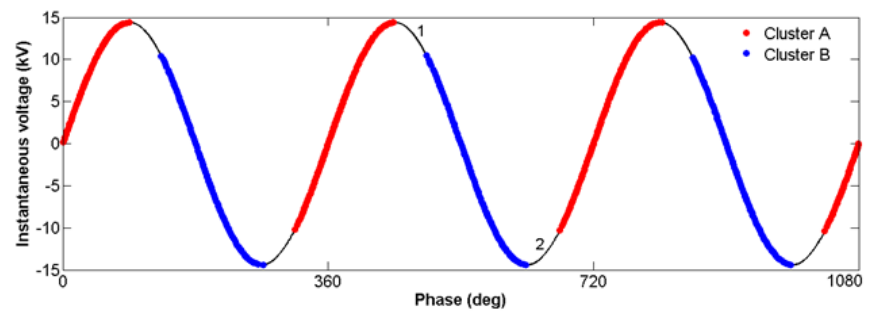

(b)

Fig. 1. The instantaneous voltage, $u(t)$, of PD occurrence overlaid on Wave 7 at (a) 10 minutes and (b) 75 minutes

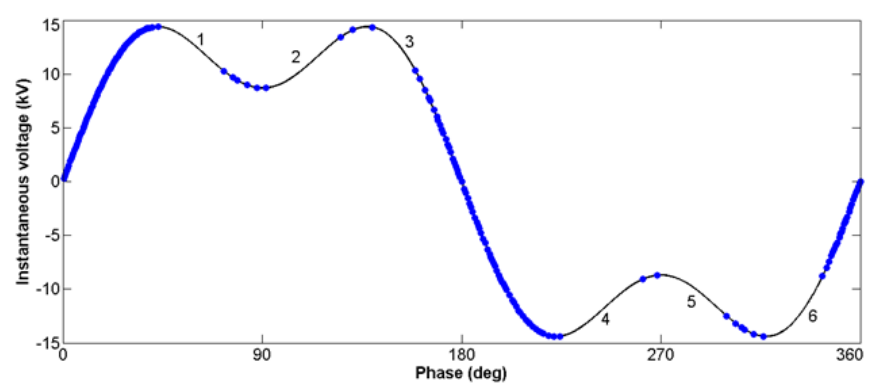

Fig. 2. The instantaneous voltage, $u(t)$, of PD occurrence overlaid on Wave 1

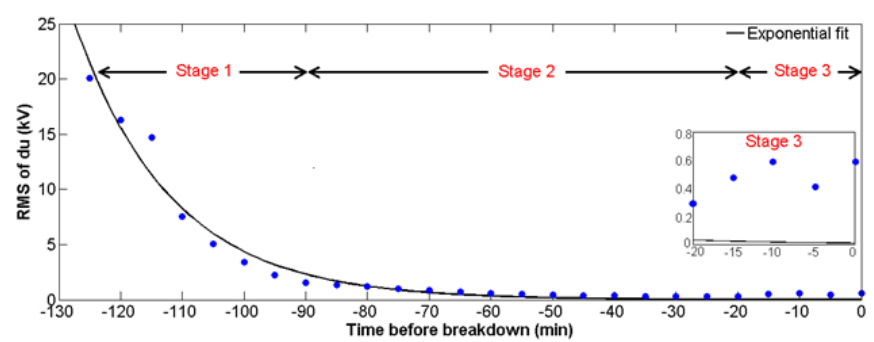

Fig. 3. The RMS of voltage change, $\Delta U_{r m s}$, for a sample tested with Wave 7 


\section{EFFECT OF NORMALIZATION ON $\Delta U_{R M S}$}

The training data employed here is from 18 samples exposed to different composite waveforms. As mentioned in Section III, plots generated under different waveforms behave slightly differently in terms of voltage change between consecutive PD pulses. However, using the $\Delta U_{R M S}$ as the ageing indicator removes the distinctive features of different test waveforms since it is an average measure.

In order to normalize the $\Delta U_{R M S}$ of all training data to a range between 0 and 1, equation (10) is used. Fig. 4 shows the exponential fitting of the normalized $\Delta U_{R M S}$ displayed to enable comparison of (a) test waveforms, (b) THD and (c) $K_{s}$.

Since the number of samples for each group might not be sufficient for robust comparison, groups with larger numbers of samples will be briefly compared. In Fig. 4a, Waves 11 and 13 have four samples each. It can be seen that variation in time to breakdown of samples under Wave 11 is greater than under Wave 13, perhaps because Wave 13 has lower values of THD and $K_{s}$. However, when considering the 5\% THD in Fig. 4b and $K_{s}$ of 1.6 in Fig. 4c (which have 8 and 6 samples respectively), both show a large variation.

$$
\Delta U_{r m s(\text { Normalized }), i}=\frac{\Delta U_{r m s, i}-\Delta U_{r m s, \min }}{\Delta U_{r m s, \max }-\Delta U_{r m s, \min }}
$$

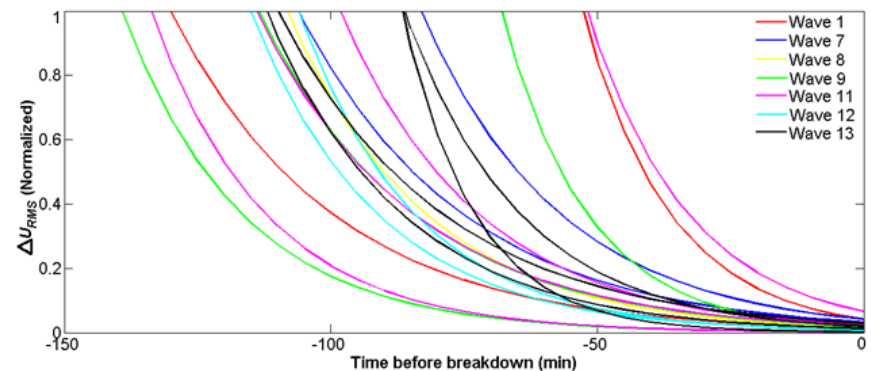

(a)

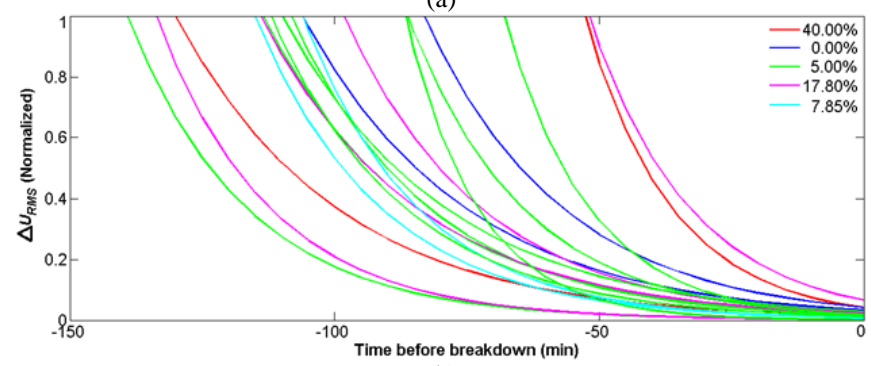

(b)

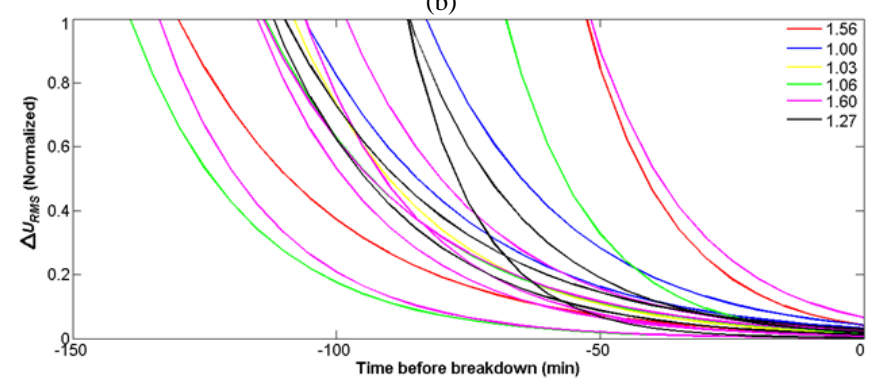

(c)

Fig. 4. The plot of normalized $\Delta U_{R M S}$ as the function of (a) Test Waveforms, (b) Total harmonic distortion (THD) and (c) Waveshape factor, $\left(K_{s}\right)$

\section{PRognostic Modelling}

In this paper a simple modeling approach is considered with the aim of predicting the $\Delta U_{R M S}$ value during breakdown $(t=0)$. The first step is to get an average model from all the training samples in Fig. 4a. Since Stage 2 and 3 (in Fig. 3) show a linear distribution with slope nearly zero, a logrithmic scale is applied on the $y$ axis for a greater range. Next, an average model is calculated giving the linear equation (11) with the value of $\log _{10} \Delta U_{R M S}$ when breakdown occurred equal to -1.86 as shown in Fig. 5. The significance of the sample name shown in Fig. 5 can be found in [8].

Since the values of $\log _{10} \Delta U_{R M S}$ at breakdown vary between samples, it is beneficial to calculate the uncertainty [9], obtaining an upper and lower limit of the $\log _{10} \Delta U_{R M S}$ during breakdown. In this study, standard deviation (sd) of $\log _{10} \Delta U_{R M S}$ is calculated yielding the two new functions (12) and (13), with breakdown values shown in Fig. 5. Finally, the breakdown value is summarized in (14).

$$
\begin{gathered}
\log _{10} \Delta U_{R M S(\text { average })}=-0.019 t-1.86 \\
\log _{10} \Delta U_{R M S(\text { upper })}=-0.021 t-1.41 \\
\log _{10} \Delta U_{R M S(\text { lower })}=-0.017 t-2.31 \\
\log _{10} \Delta U_{R M S(\text { breakdown })}=-1.86 \pm 0.45
\end{gathered}
$$

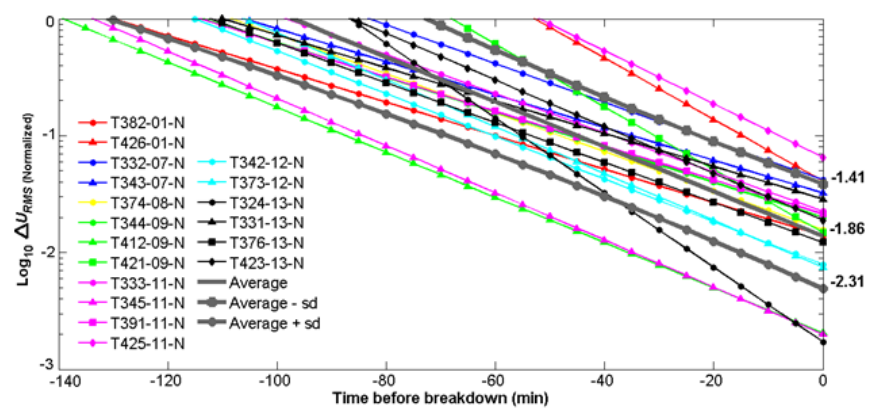

Fig. 5. The prognostic model of electrical treeing in epoxy resin with upper and lower bounds. The symbols on the curves are to aid identification and are not experimental data points.

\section{MOdel VALIDATION}

Seven samples with complete breakdown data were selected randomly from each test waveform in order to validate the model developed in Section VI. The breakdown time for every sample is in the range of 77 to 140 minutes. In this study, 3 subsets of the data were examined individually:
1. From 0 to 25 minutes
2. From 0 to 50 minutes
3. From 0 to 75 minutes

The reason for examining the data in three different windows was to measure the accuracy of the prognosis depending on the amount of available data. The validation process for each sample repeats the steps discussed in Sections III to VI as summarized below: 
Step 1: Calculate the voltage change $\Delta U$ between consecutive PD pulses using equations (1) to (8).

Step 2: Calculate the RMS of voltage change, $\Delta U_{R M S}$, using (9) for every 5 minutes for the 25, 50 and 75 minute time windows.

Step 3: Calculate the normalized values of $\Delta U_{R M S}$.

Step 4: Apply the exponential fit to the normalized $\Delta U_{R M S}$.

Step 5: Convert the exponential plot from Step 4 to log-linear scale.

Step 6: Extrapolate the linear plot in Step 5 to determine the estimated breakdown time, $t_{b d}$, and the bounds when $\log _{10} \Delta U_{R M S}$ equals to $-1.8622 \pm 0.45$

Fig. 6 illustrates Step 6 for a sample exposed to Wave 12 when only 25 minutes of data is available. The results of this analysis can be seen in Table 2. The error, $e$, is calculated using (15). In general, all sample data showed the exponentially decreasing trend until 60 min growth, thus, the $50 \mathrm{~min}$ and 75 min subset data should give better estimated breakdown times than the 25 min subset. Most of the 25 min data gives a large error, especially sample T392-08-N, which gives a negative estimated breakdown time. Between the 50 and $75 \mathrm{~min}$ data, the 50 min subset gives the least error even although the 75 min window has more input data is available. One possible reason is that the 75 min subset may contain data from Stage 2 (Fig. 3), giving a mix of exponential and linear decrease, whereas the 50 min subset gives only exponential data. Among the 7 testing samples, sample T372-11-N has the largest error for the 50 and 75 min windows, because Stage 1 of the growth looks closer to a linear trend rather than an exponential one.

$$
e=\left|\frac{\text { Actual breakdown }- \text { Estimated breakdown }}{\text { Actual breakdown }}\right|
$$

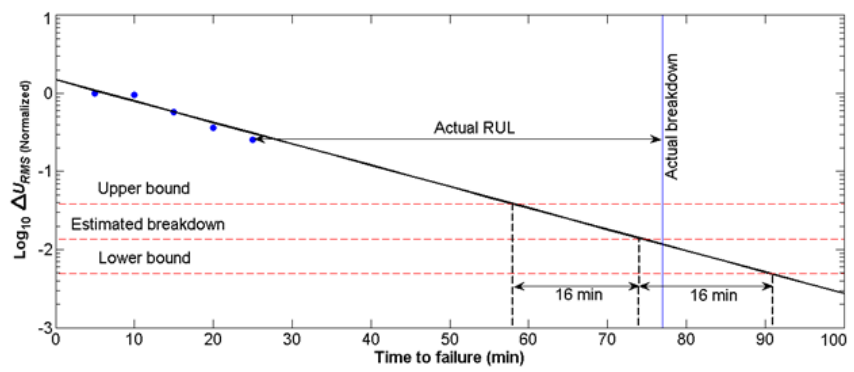

Fig. 6. Estimation of breakdown time for sample T424-12-N with 25 min data

\section{CONCLUSIONS AND FUTURE WORK}

The aim of this work was to investigate prognostic modeling of breakdown due to electrical treeing in epoxy resin samples. The results show that it is possible to predict failure before the actual breakdown occurs, within 1 standard deviation of the training data at 50 and 75 min horizons. This suggests that the proposed framework can be used to model and trend failure of insulation due to electrical treeing, and that the change in external voltage is an appropriate parameter for prognostic prediction. Future work will consider ways of reducing prediction error, and test with different samples considering longer tree growth and different types of tree.

\section{ACKNOWLEDGMENT}

VMC and SMR acknowledge the EPRSC for the support of this work through the Supergen HubNet project EP/I013636/1.

\section{REFERENCES}

[1] L. A. Dissado, "Understanding electrical trees in solids: from experiment to theory," IEEE Trans. Dielectrics and Electrical Insulation, vol. 9, no. 4, pp. 483-497, 2002.

[2] S. Dodd, N. Chalashkanov, and J. Fothergill, "Partial discharge patterns in conducting and non-conducting electrical trees," in 10th IEEE Int. Conf. Solid Dielectrics (ICSD), 2010.

[3] R. Patsch and F. Berton, "Pulse Sequence Analysis-a diagnostic tool based on the physics behind partial discharges," Journal of Physics D: Applied Physics, vol. 35, no. 1, p. 25, 2002.

[4] S. Strachan, S. Rudd, S. McArthur, M. Judd, S. Meijer, and E. Gulski, "Knowledge-based diagnosis of partial discharges in power transformers," IEEE Trans. Dielectrics and Electrical Insulation, vol. 15, no. 1, pp. 259-268, 2008.

[5] L. A. Dissado, "Predicting electrical breakdown in polymeric insulators. From deterministic mechanisms to failure statistics," IEEE Trans. Dielectrics and Electrical Insulation, vol. 9, no. 5, pp. 860-875, 2002.

[6] N.H. Aziz, M.D. Judd, and V.M. Catterson, "Identifying prognostic indicators for electrical treeing in solid insulation through PD analysis," in IEEE Int. Conf. Solid Dielectrics (ICSD), 2013, pp. 152-155.

[7] S. Bahadoorsingh and S. Rowland, "Investigating the impact of harmonics on the breakdown of epoxy resin through electrical tree growth,” IEEE Trans. Dielectrics and Electrical Insulation, vol. 17, no. 5, pp. 1576-1584, 2010.

[8] S. Bahadoorsingh and S. Rowland, "Investigating the influence of the lubricant coating on hypodermic needles on electrical tree characteristics in epoxy resin," IEEE Trans. Dielectrics and Electrical Insulation, vol. 17, no. 3, pp. 701-708, 2010.

[9] S. Rudd, V.M. Catterson, S.D.J. McArthur, and C. Johnstone, "Circuit breaker prognostics using SF6 data," in IEEE Power and Energy Society General Meeting, 2011.

TABLE 2

Prognosis of Epoxy Resin SAmples

\begin{tabular}{|c|c|c|c|c|c|c|c|c|c|c|}
\hline \multirow{2}{*}{ Samples } & \multirow{2}{*}{$\begin{array}{l}\text { Actual } \\
\text { b/down } \\
\text { time } \\
\text { (min) }\end{array}$} & \multicolumn{2}{|c|}{$25 \mathrm{~min}$} & \multicolumn{2}{|c|}{$50 \mathrm{~min}$} & \multicolumn{2}{|c|}{$75 \mathrm{~min}$} & \multirow{2}{*}{\multicolumn{3}{|c|}{$\begin{array}{l}\text { The actual breakdown time is } \\
\text { indicated with colors according to } \\
\text { the following regions: }\end{array}$}} \\
\hline & & $\begin{array}{l}\text { Estimated } \\
\text { b/d time } \\
\text { (min) }\end{array}$ & $\begin{array}{c}\text { Error, } e \\
(\%)\end{array}$ & $\begin{array}{l}\text { Estimated } \\
\text { b/d time } \\
\text { (min) }\end{array}$ & $\begin{array}{c}\text { Error, } e \\
(\%)\end{array}$ & $\begin{array}{l}\text { Estimated } \\
\text { b/d time } \\
\text { (min) }\end{array}$ & $\begin{array}{c}\text { Error, } e \\
(\%)\end{array}$ & & & \\
\hline T346-01-N & 115 & $55 \pm 12$ & 52 & $126 \pm 31$ & 10 & $138 \pm 35$ & 20 & & Estimated & \\
\hline T355-07-N & 115 & $163 \pm 38$ & 42 & $99 \pm 22$ & 14 & $95 \pm 21$ & 17 & Upper & breakdown & Lower \\
\hline T392-08-N & 140 & - & - & $150 \pm 36$ & 7 & $131 \pm 30$ & 6 & boundary & time & boundary \\
\hline T381-09-N & 107 & $100 \pm 23$ & 7 & $95 \pm 21$ & 11 & $94 \pm 22$ & 12 & & & \\
\hline T372-11-N & 129 & $189 \pm 45$ & 31 & $161 \pm 38$ & 25 & $168 \pm 39$ & 30 & & & \\
\hline T424-12-N & 77 & $74 \pm 16$ & 4 & $73 \pm 16$ & 5 & $74 \pm 16$ & 4 & & & \\
\hline T363-13-N & 125 & $281 \pm 65$ & 125 & $115 \pm 26$ & 8 & $108 \pm 24$ & 14 & & & \\
\hline
\end{tabular}

